\title{
Modern biotechnology-based therapeutic approaches against HIV infection (Review)
}

\author{
MUHAMMAD IMRAN $^{1 *}$, YASIR WAHEED ${ }^{2}$, AYESHA GHAZAL $^{1}$, SAJJAD ULLAH $^{3}$, SHER ZAMAN SAFI $^{4}$, \\ MUHSIN JAMAL ${ }^{5}$, MUHAMMAD ALI $^{6}$, MUHAMMAD ATIF $^{7}$, MUHAMMAD IMRAN $^{8}$ and FARMAN ULLAH ${ }^{9}$
}

${ }^{1}$ Department of Microbiology, University of Health Sciences, Lahore 54600; ${ }^{2}$ Foundation University Medical College, Foundation University, Islamabad 44000; ${ }^{3}$ Department of Medical Laboratory Sciences, Imperial College of Business Studies, Lahore 53720; ${ }^{4}$ Interdisciplinary Research Center in Biomedical Materials (IRCBM), COMSATS Institute of Information Technology, Lahore 54000; ${ }^{5}$ Department of Microbiology, Abdul Wali Khan University, Garden Campus, Mardan 23200;

${ }^{6}$ Department of Life Sciences, University of Management Technology, Lahore 54600, Pakistan;

${ }^{7}$ Department of Clinical Laboratory Sciences, College of Applied Medical Sciences, Aljouf University, Sakaka,

Saudi Arabia; ${ }^{8}$ Department of Diet and Nutrition, Imperial College of Business Studies, Lahore 54600; ${ }^{9}$ Department of Physiology, Shaheed Zulfiqar Ali Bhutto Medical university Islamabad, Islamabad 44000, Pakistan

Received August 18, 2017; Accepted September 27, 2017

DOI: $10.3892 / b r .2017 .1006$

\begin{abstract}
The causative agent of acquired immune deficiency syndrome (AIDS) is human immunodeficiency virus (HIV). Since its discovery before 30 years, a number of drugs known as highly active antiretroviral therapy have been developed to suppress the life cycle of the virus at different stages. With the current therapeutic approaches, ending AIDS means providing treatment to 35 million individuals living with HIV for the rest of their lives or until a cure is developed. Additionally, therapy is associated with various other challenges such as potential of drug resistance, toxicity and presence of latent viral reservoir. Therefore, it is imperative to search for treatments and to identify new therapeutic approaches against HIV infection to avoid daily intake of drugs. The aim of the current review was to summarize different therapeutic strategies against HIV infection, including stem cell therapy, RNA interference, CRISPR/Cas9 pathways, antibodies, intrabodies and nanotechnology. Silencing RNA against chemokine receptor 5 and other HIV RNAs have been tested and found to elicit homology-based, post-transcriptional silencing. The CRISPR/Cas9 is a gene editing technology that produces a double-stranded nick in the virus DNA, which is repaired by the host machinery either by non-homology end joining mechanism or via homology recombination leading to insertion, deletion mutation which further leads to frame shift mutation and non-functional products. Intrabodies are
\end{abstract}

Correspondence to: Dr Muhammad Imran, Department of Microbiology, University of Health Sciences, Khayaban-e-Jamia Punjab, Lahore 54600, Pakistan

E-mail: mi.bannu@yahoo.com

Key words: antibodies, CRISPR/Cas9, drugs, HIV, nanomedicine, RNAi, stem cell, therapy intracellular-expressed antibodies that are directed towards the targets inside the cell unlike the naturally expressed antibodies which target outside the cell. Different nanotechnology-based therapeutic approaches are also in progress against HIV. HIV eradication is not feasible without deploying a cure or vaccine alongside the treatment.

\section{Contents}

1. Introduction

2. Stem cell therapy

3. RNAi

4. CRISPR/Cas9

5. Antibody-based therapeutic approaches against HIV infection

6. Antibodies inside the cell

7. Nanotechnology against HIV infection

8. Conclusions

\section{Introduction}

Acquired immunodeficiency syndrome (AIDS) was identified in 1981 (1). Subsequently, it was found that the causative agent of AIDS was HIV. Currently, over 35 million individuals are HIV infected worldwide with the highest prevalence being in Sub-Saharan African countries (2,3). HIV type 1 is the most prevalent type of this virus (4). Since the year 2000, there has been a reduction in the number of new cases of HIV infection from 3.1 to 2 million globally (3). Moreover, the number of HIV infected subjects on antiretroviral therapy has increased from 1 to 15 million. The main reason behind this achievement was raising the fund against HIV infection from $\$ 4.9$ to $\$ 21.7$ billion (5). Thus, throughout there is struggling to manage HIV infection and to a greater extent there has been 
success in achieving this target. Nevertheless, the eradication of HIV remains a target.

Human immunodeficiency virus attacks the immune system and leads to the development of AIDS. The natural history of HIV infection is diverse. The average duration required for infection to reach the stage of AIDS is 8-10 years. Approximately 5-10\% of HIV-exposed subjects remain asymptomatic even though they do not take any retroviral drugs, and are known as long-term non-progressors $(6,7)$. The presence of such groups of HIV-infected subjects highlights the fact that there is natural resistance to the virus. The exploration of the host natural resistance against the virus may lead to the development of novel therapeutic approaches.

Drug development against HIV infection is a challenging task. HIV is a retrovirus with high variability in its genome due to a lack of proofreading exo-nuclease activity in its reverse transcriptase enzyme. The high genome variability of HIV genome in a patient results in the production of quasi-species and drug resistance against previously effective drugs (8). Therefore, researchers are seeking better therapeutic approaches against HIV infection. These approaches are discussed below.

\section{Stem cell therapy}

The first step of HIV life cycle is its binding and entry into the host cell. The HIV envelop protein (Env) binds with its receptor and co-receptor on the target cell. The HIV Env protein is a heavily glycosylated trimer of gp120 and gp41 proteins. CD4 is a member of the immunoglobulin superfamily and acts as a receptor, while chemokine receptor (CCR) 5 or chemokine $\mathrm{X}$ receptor 4 (CXCR4) acts as a co-receptor for viral entry into the host cell. The viruses that exploit CCR5 or CXCR4 are termed R5 and X4 HIV virions, respectively, while those using both CCR5 and CXCR4 as co-receptors are known as R5X4 HIV virions $(9,10)$. However, HIV viruses that are transmitted by sexual contact, percutaneous inoculation or maternal routes, are R5 viruses (11). Thus CCR5 plays an important role in HIV entrance into the host cell. The deletion mutation, $\Delta 32$ CCR5 results in the production of defective protein. The homozygous condition of $\Delta 32$ CCR5 prevents HIV infection as the virus cannot enter the host cell. Furthermore, the stem cell therapy from a homozygous $\Delta 32$ CCR 5 deletion mutated donor to the HIV-infected patients demonstrated a successful therapeutic option (12-14). However, the duplication of this experiment was failed in six other patients highlighting that this therapeutic approach is extremely difficult (13). Furthermore, the problem with allogeneic stem-cell transplantation from an HLA-matched donor, is the low availability of donors and high risk associated with allogeneic stem-cell transplantation.

Another approach of gene therapy is to permanently disable CCR5 by zinc finger nuclease (NCT00842634). Zinc finger nucleases are genomic scissors comprising DNA binding and cleaving domains (15). The main limitation of this genome editing technology is the overlapping of individual zinc finger specificity. In a clinical trial commencing in 2014, SB-728mR-T treatment was delivered using many ex vivo adenovirus expanded transduced autologous $\mathrm{CD}^{+} \mathrm{T}$ cells into $12 \mathrm{HIV}$-infected patients. No severe side effects of transduction were reported. For substantial effects of transduction, biallelic transduction of CCR5 is required.
However, in the majority of circulating autologous $\mathrm{CD}^{+} \mathrm{T}$ cases, there was knockdown of one CCR5 allele. The study is currently ongoing (NCT00842634) and is to be completed in June, 2018 (16).

\section{RNAi}

Preclinical studies have shown that small interfering RNAs are less immunogenic than protein-based agents and potent inhibitors (14). Silencing RNA (siRNAs) against CCR5 $(17,18)$ and other HIV RNAs (19-22) have been tested and found to elicit homology-based, post-transcriptional silencing. Taken together, it was concluded that the efficacy of this technique is highly dependent on various factors including the use of vectors and promoters for the expression of siRNAs and selection cassette combinations for controlling HIV infection (23).

\section{CRISPR/Cas9}

The most previously used gene editing technology for targeting HIV infection is clustered regularly interspaced short palindromic repeats (CRISPR)-associated protein-9 nuclease (Cas9). The technology comprises CRISPR RNA (crRNA) and trans-activating CRISPR RNA (tracr RNA). crRNA and tracr RNA are collectively known as guide RNA (gRNA) which directs caspase-9 to the target site (24). The target site is 20 nucleotide DNA sequences, which is complementary to crRNA and is followed by protospacer adjacent motif (PAM) of 3 nucleotides (NGG). Caspase-9 produces double-stranded nick just before PAM sequence. The double-stranded nicks produced in DNA are repaired by host machinery via non-homology end joining mechanism or homologous recombination leading to insertion, and deletion mutation, which further leads to frame shift mutation and non-functional products (25). To avoid off-target sites of this technology alternation in caspase- 9 nuclease is induced, resulting in the production of single-strand nick in DNA (26). The repair mechanism requires two target sites in close proximity and the likelihood of off-target sites are substantially reduced. The technology is limited to only those target sequences that are 20 nucleotides in length and followed by PAM. Moreover, certain target sequences are problematic due to the formation of secondary RNA structures. Most previously engineered RNA-guided FokI-nucleases have been used to improve the cleavage efficacy and broader genome targetibility (27).

Previous studies of 1-cell mouse embryos demonstrated that the cytoplasmic microinjection of gRNA and CAS9 mRNA to generate enhancer knockout mouse lines possessed a range of putative off-target sites (28). However, sequencing of amplified products showed that there were no off-target effects in the genomes (28). The study results suggested that the potential off-target effects of CRISPR/CAS9 technology are exaggerated. Thus, this technology is highly effective and accurate for deleting putative gene enhancer sequences from the mouse genome (28).

\section{Antibody-based therapeutic approaches against HIV infection}

Antibody-based therapeutic approaches against HIV infection have had limited success thus far. The main reason behind 
this therapeutic approach is its transient effect and specificity. Recently recombinant adenoassociated virus (rAAV) vector is used as a delivery mechanism of broadly neutralizing (bnAbs) anti-HIV antibodies in monkeys and mice and it demonstrated long-lasting immune responses (29). The genetically modified rAAV persists in the cell and only produces the gene of interest for the entire life of cell $(30,31)$. However, some unwanted immune responses which limit the efficacy of these bnAbs have also been identified (29).

\section{Antibodies inside the cell}

Intrabodies are intracellular-expressed antibodies that are directed towards the targets inside the cell unlike the naturally expressed antibodies which target the outside of the cell. An intrabody approach functions with single antigen binding fragment or may even contain a single domain (nanobodies). However, the cytosolic expression of intrabodies may lead to the production of non-functional antibodies due to misfolding $(32,33)$. To overcome the problem, such intrabodies are produced that are, not only specific towards their targets (functional knockdown of membrane protein or some other protein), but may also possess an endoplasmic reticulum (ER) retention signal, the amino acid signal (34). Thus, the intrabody is retained with its target inside the ER (34).

\section{Nanotechnology against HIV infection}

Nanotechnology is an emerging field of science and technology that is revolutionizing the medical field. Typically, nanoparticles range from 1 to $100 \mathrm{~nm}$ in size in at least one dimension (35). Nanoparticles are more commonly referred to as nanomedicines and are used for the prevention and diagnosis of infections (36). In some cases, the healing and therapeutic potential of nanomedicines have also been reported $(37,38)$. Most of its applications are reported in the field of cancer. Multiplte nanosystems are either Food and Drugs Authority approved or in clinical trials for the treatment of systematic cancer $(38,39)$. The success of nanomedicines are attributed to improved delivery of poor water soluble drugs, targeted delivery to cells or tissues, intracellular delivery of macromolecules and controlled release of drug at its target site $(35,39,40)$.

Nanomedicines against HIV infection have also been previously investigated. Experiments on mice have shown that nanosuspension of indinavir (a retroviral drug against HIV infection) was stabilized by a surfactant system for effective delivery to various tissues $(40,41)$. The nanosuspension of indinavir was loaded on macrophages and its uptake was identified in different tissues including spleen, liver, lungs and brain. Moreover, the half life of conventionally delivered indinavir in rodents was $2 \mathrm{~h}$, while a single dose of intravenously injected nanoindavir suspension in rodents was measurable in the blood up to 14 days post-treatment (41). It was observed that the cellular uptake of satuvudine (HIV nucleoside analog reverse transcriptase inhibitor) encapsulated in various liposomes and conjugated with mannose and galactose was also increased as compared to plain liposomes or free drugs $(41,42)$.

In addition to delivery agents, nanomaterials as therapeutic agents have also been reported. It has been shown that the capsid structure of HIV may be used as a target for structure-based drugs to inhibit viral replication $(43,44)$. The in vitro anti-HIV activity of various fullerene-based structures including dendrimers and inorganic particles such as gold and silver have already been previously reported (45-47).

\section{Conclusions}

The only available solution of HIV-infected subjects is highly active antiretroviral therapy and the drugs are used in combination to suppress the virus at any stage of its life cycle. These drugs only increase the life span of the subjects and do not provide a permanent cure. Therefore, different novel therapeutic approaches against HIV, which include stem cell therapy, genome editing, antibodies, and nanotechnology are under investigation. Among these technologies, CRISPR/Cas9, genome editing technology seems to be the most potential therapeutic approach against HIV infection.

\section{Acknowledgements}

The present study was supported by Department of Microbiology, University of Health Sciences and Faculty of Health.

\section{References}

1. Faulstich ME: Acquired immune deficiency syndrome: An overview of central nervous system complications and neuropsychological sequelae. Int J Neurosci 30: 249-254, 1986.

2. Kharsany $A B$ and Karim QA: HIV Infection and AIDS in Sub-Saharan Africa: Current Status, Challenges and Opportunities. Open AIDS J 10: 34-48, 2016.

3. Granich R, Gupta S, Hersh B, et al: Trends in AIDS Deaths, New Infections and ART Coverage in the Top 30 Countries with the Highest AIDS Mortality Burden; 1990-2013. PloS one 10: 2015.

4. Imran M, Manzoor S, Saalim M, Resham S, Ashraf J, Javed A and Waqar AB: HIV-1 and hijacking of the host immune system: The current scenario. APMIS 124: 817-831, 2016.

5. Waheed Y and Waheed H: Pakistan needs to speed up its human immunodeficiency virus control strategy to achieve targets in fast-track acquired immune deficiency syndrome response. World J Virol 6: 46-48, 2017.

6. Piacentini L, Fenizia C, Naddeo V and Clerici M: Not just sheer luck! Immune correlates of protection against HIV-1 infection. Vaccine 26: 3002-3007, 2008.

7. Walker BD: Elite control of HIV Infection: Implications for vaccines and treatment. Top HIV Med 15: 134-136, 2007.

8. Roberts JD, Bebenek K and Kunkel TA: The accuracy of reverse transcriptase from HIV-1. Science 242: 1171-1173, 1988.

9. Wilen CB, Tilton JC and Doms RW: HIV: Cell binding and entry Cold Spring Harb Perspect Med 2: a006866, 2012.

10. Ray N and Doms R: HIV-1 Coreceptors and their inhibitors. Curr Top Microbiol Immunol 303: 97-120, 2006.

11. Shaw G and Hunter E: HIV transmission. Cold Spring Harb Perspect Med 2: a006965, 2012.

12. Hütter G, Nowak D, Mossner M, Ganepola S, Müssig A, Allers K, Schneider T, Hofmann J, Kücherer C, Blau O, et al: Long-term control of HIV by CCR5 Delta32/Delta32 stem-cell transplantation. N Engl J Med 360: 692-698, 2009.

13. Allers K, Hütter G, Hofmann J, Loddenkemper C, Rieger K, Thiel $\mathrm{E}$ and Schneider T: Evidence for the cure of HIV infection by CCR $5 \Delta 32 / \Delta 32$ stem cell transplantation. Blood 117: 2791-2799, 2011.

14. Spanevello F, Calistri A, Del Vecchio C, Mantelli B, Frasson C, Basso G, Palù G, Cavazzana M and Parolin C: Development of lentiviral vectors simultaneously expressing multiple siRNAs against CCR5, vif and tat/rev genes for an HIV-1 gene therapy approach. Mol Ther Nucleic Acids 5: e312, 2016. 
15. Chandrasegaran S and Carroll D: Origins of Programmable Nucleases for Genome Engineering. J Mol Biol 428: 963-989, 2016.

16. Tebas P, Stein D, Tang WW, Frank I, Wang SQ, Lee G, Spratt SK, Surosky RT, Giedlin MA, Nichol G, et al: Gene editing of CCR5 in autologous CD4 T cells of persons infected with HIV. N Engl J Med 370: 901-910, 2014.

17. Zeller SJ and Kumar P: RNA-based gene therapy for the treatment and prevention of HIV: From bench to bedside. Yale J Biol Med 84: 301-309, 2011.

18. An DS, Donahue RE, Kamata M, Poon B, Metzger M, Mao SH, Bonifacino A, Krouse AE, Darlix JL, Baltimore D, et al: Stable reduction of CCR5 by RNAi through hematopoietic stem cell transplant in non-human primates. Proc Natl Acad Sci USA 104: 13110-13115, 2007.

19. Shimizu S, Kamata M, Kittipongdaja P, Chen KN, Kim S, Pang S, Boyer J, Qin FX, An DS and Chen IS: Characterization of a potent non-cytotoxic shRNA directed to the HIV-1 co-receptor CCR5. Genet Vaccines Ther 7: 8, 2009.

20. Jacque JM, Triques K and Stevenson M: Modulation of HIV-1 replication by RNA interference. Nature 418: 435-438, 2002.

21. Lee SK, Dykxhoorn DM, Kumar P, Ranjbar S, Song E, Maliszewski LE, François-Bongarçon V, Goldfeld A, Swamy NM, Lieberman J, et al: Lentiviral delivery of short hairpin RNAs protects CD4 T cells from multiple clades and primary isolates of HIV. Blood 106: 818-826, 2005.

22. Sander JD and Joung JK: CRISPR-Cas systems for editing, regulating and targeting genomes. Nature Biotechnology 32: 347-355, 2014.

23. Liu YP, Haasnoot J and Berkhout B: Design of extended short hairpin RNAs for HIV-1 inhibition. Nucleic Acids Res 35: 5683-5693, 2007.

24. Novina CD, Murray MF, Dykxhoorn DM, Beresford PJ, Riess J, Lee SK, Collman RG, Lieberman J, Shankar P and Sharp PA: siRNA-directed inhibition of HIV-1 infection. Nat Med 8 : 681-686, 2002

25. Wang W, Ye C, Liu J, Zhang D, Kimata JT and Zhou P: CCR5 gene disruption via lentiviral vectors expressing Cas9 and single guided RNA renders cells resistant to HIV-1 infection. PLOS One 9: e115987, 2014.

26. Ran FA, Hsu PD, Lin CY, Gootenberg JS, Konermann S, Trevino AE, Scott DA, Inoue A, Matoba S, Zhang Y, et al: Double nicking by RNA-guided CRISPR Cas9 for enhanced genome editing specificity. Cell 154: 1380-1389, 2013

27. Havlicek S, Shen Y, Alpagu Y, Bruntraeger MB, Zufir NB, Phuah ZY, Fu Z, Dunn NR and Stanton LW: Re-engineered RNA-guided FokI-nucleases for improved genome editing in human cells. Mol Ther 25: 342-355, 2017.

28. Hay EA, Khalaf AR, Marini P, Brown A1, Heath K1, Sheppard D, and MacKenzie A: An analysis of possible off target effects following CAS9/CRISPR targeted deletions of neuropeptide gene enhancers from the mouse genome. Neuropeptides 64: 101-107, 2017.

29. Fuchs SP and Desrosiers RC: Promise and problems associated with the use of recombinant AAV for the delivery of anti-HIV antibodies. Mol Ther Methods Clin Dev 3: 16068, 2016.

30. Schnepp BC, Clark KR, Klemanski DL, Pacak CA and Johnson PR: Genetic fate of recombinant adeno-associated virus vector genomes in muscle. J Virol 77: 3495-3504, 2003.

31. Schnepp BC, Chulay JD, Ye G-J, Flotte TR, Trapnell BC and Johnson PR: Recombinant adeno-associated virus vector genomes take the form of long-lived, transcriptionally competent episomes in human muscle. Hum Gene Ther 27: 32-42, 2016.
32. Biocca S, Ruberti F, Tafani M, Pierandrei-Amaldi P and Cattaneo A: Redox state of single chain Fv fragments targeted to the endoplasmic reticulum, cytosol and mitochondria. Biotechnology (N Y) 13: 1110-1115, 1995.

33. Stocks M: Intrabodies as drug discovery tools and therapeutics. Curr Opin Chem Biol 9: 359-365, 2005.

34. Lewis MJ and Pelham HR: Ligand-induced redistribution of a human KDEL receptor from the Golgi complex to the endoplasmic reticulum. Cell 68: 353-364, 1992.

35. Farokhzad OC: Nanotechnology for drug delivery: The perfect partnership. Expert Opin Drug Deliv 5: 927-929, 2008.

36. Zhang L, Gu FX, Chan JM, Wang AZ, Langer RS and Farokhzad OC: Nanoparticles in medicine: Therapeutic applications and developments. Clin Pharmacol Ther 83: 761-769, 2008

37. Ferrari M: Cancer nanotechnology: Opportunities and challenges. Nat Rev Cancer 5: 161-171, 2005.

38. Nie S, Xing Y, Kim GJ and Simons JW: Nanotechnology applications in cancer. Annu Rev Biomed Eng 9: 257-288, 2007.

39. Davis ME, Chen ZG and Shin DM: Nanoparticle therapeutics: An emerging treatment modality for cancer. Nat Rev Drug Discov 7: 771-782, 2008.

40. Mamo T, Moseman EA, Kolishetti N, Salvador-Morales C, Shi J, Kuritzkes DR, Langer R, von Andrian U and Farokhzad OC: Emerging nanotechnology approaches for HIV/AIDS treatment and prevention. Nanomedicine (Lond) 5: 269-285, 2010.

41. Dou H, Grotepas CB, McMillan JM, Destache CJ, Chaubal M, Werling J, Kipp J, Rabinow B and Gendelman HE: Macrophage delivery of nanoformulated antiretroviral drug to the brain in a murine model of neuroAIDS. J Immunol 183: 661-669, 2009

42. Garg M, Garg BR, Jain S, Mishra P, Sharma RK, Mishra AK, Dutta $\mathrm{T}$ and Jian NK: Radiolabeling, pharmacoscintigraphic evaluation and antiretroviral efficacy of stavudine loaded 99mTc labeled galactosylated liposomes. Eur J Pharm Sci 33: 271-281, 2008

43. Ganser-Pornillos BK, Yeager $M$ and Sundquist WI: The structural biology of HIV assembly. Curr Opin Struct Biol 18: 203-217, 2008

44. Pornillos O, Ganser-Pornillos BK, Kelly BN, Hua Y, Whitby FG, Stout CD, Sundquist WI, Hill CP and Yeager M: X-ray structures of the hexameric building block of the HIV capsid. Cell 137: 1282-1292, 2009

45. Marchesan S, Da Ros T, Spalluto G, Balzarini J and Prato M: Anti-HIV properties of cationic fullerene derivatives. Bioorg Med Chem Lett 15: 3615-3618, 2005.

46. Troshina OA, Troshin PA, Peregudov AS, Kozlovskiy VI, Balzarini J and Lyubovskaya RN: Chlorofullerene C60C16: A precursor for straightforward preparation of highly water-soluble polycarboxylic fullerene derivatives active against HIV. Org Biomol Chem 5: 2783-2791, 2007.

47. Wang W, Guo Z, Chen Y, Liu T and Jiang L: Influence of generation 2-5 of PAMAM dendrimer on the inhibition of Tat peptide/ TAR RNA binding in HIV-1 transcription. Chem Biol Drug Des 68: 314-318, 2006. 